\title{
Polymeric hollow fiber heat exchangers
}

\author{
M. Raudenský, I. Astrouski \& T. Bozova \\ Heat Transfer and Fluid Flow Laboratory, \\ Faculty of Mechanical Engineering, \\ Brno University of Technology, Czech Republic
}

\begin{abstract}
Metallic heat exchangers have a number of well-known shortcomings such as high weight and cost and low resistance to corrosion. Polymeric hollow fiber heat exchangers were proposed about a decade ago as an alternative for low temperature applications. Although experimental results have been published for liquid-to-liquid applications, there is no data for liquid-to-gas applications. To overcome this lack of data, two liquid-to-air cross-flow heat exchangers were prepared and tested. Two types of polypropylene hollow fibers (wall thickness $50 \mu \mathrm{m}$, outside diameter $800 \mu \mathrm{m}$ and $600 \mu \mathrm{m}$ ) were used to create heat exchangers with a heat exchange area of approximately $0.6 \mathrm{~m}^{2}$. An original approach (fiber fabrics were woven) was utilized to achieve a uniform distribution of fibers. The heat transfer performance was studied with hot liquids $\left(60-90^{\circ} \mathrm{C}\right.$ ethyleneglycolwater brine or water) flowing inside the fibers and cooling air flowing across the fibers. Experiments showed that hollow fiber cross-flow heat exchangers can achieve high values of overall heat-transfer coefficients $\left(200-450 \mathrm{~W} / \mathrm{m}^{2} \mathrm{~K}\right)$ and can compete to ordinary finned-tube heat exchangers.

Keywords: polymeric hollow fibers, heat exchanger, forced convection.
\end{abstract}

\section{Introduction}

Heat exchangers have a wide variety of applications in different fields of industry and HVACR. Currently, these applications rely heavily on heat exchangers constructed using copper, aluminium, or steel. Polymeric hollow fiber heat exchangers were proposed almost a decade ago as an alternative to low temperature applications. These devices use hollow fibers with a small diameter as heat exchange surfaces. They can be classified as micro-devices because the hollow fiber inner path is a microchannel (about $400-800 \mu \mathrm{m}$ in diameter). 
Polymers have many advantages and are one alternative. They have low weight and cost, and excellent chemical resistance. The smoothness of the polymer surface provides good fouling characteristics. This leads to a small decrease of thermal performance during operation and simplifies the maintenance. The molding and heat-sealing capabilities of thermoplastic polymer materials makes it possible to fabricate even complex shapes or very large surface areas at low cost. Polymers are environmentally friendly because they are recyclable and the energy required to produce a unit mass of polymer is approximately two times lower than that of common metals.

Polymeric Hollow Fiber Heat Exchangers (PHFHEs) for low-temperature applications were firstly proposed by Zarkadas and Sirkar [1]. Small devices containing a few hollow PP fibers with parallel flow were tested and showed good thermal performance. The OHTCs of these devices were $647-1314 \mathrm{~W} / \mathrm{m}^{2} \mathrm{~K}$ and 414-642 W/m $\mathrm{m}^{2} \mathrm{~K}$ for the water-water and ethanol-water systems, respectively. It was shown that in several cases OHTC is limited by wall thermal resistance and is independent on flow conditions. The next advantage of these devices is a possibility to achieve large packing density (surface area to volume ratio).

Song et al. [2] carried out a large experimental study of different PHFHEs with the emphasis on application for thermal desalination processes. Ten devices having different flow organization, type and number of the fibers, heat exchange area and packing density were investigated. The heat transfer performance of these devices were studied for a hot brine $\left(4 \% \mathrm{NaCl}, 80-98^{\circ} \mathrm{C}\right)$-cold water $\left(8-25^{\circ} \mathrm{C}\right)$ system and for a steam $\left(101-113^{\circ} \mathrm{C}\right)$-cold water $\left(8-25^{\circ} \mathrm{C}\right)$ system because these systems are typically encountered in thermal desalination plants. OHTC values about $2000 \mathrm{~W} / \mathrm{m}^{2} \mathrm{~K}$ for brine-water systems and $1600-1800 \mathrm{~W} / \mathrm{m}^{2} \mathrm{~K}$ for steamwater system were achieved. Surface area per unit volume of tested devices was up to $4000 \mathrm{~m}^{2} / \mathrm{m}^{3}$ and their volumetric rate of heat transfer was very high. Moreover, authors concluded that compared to metallic heat exchangers used in desalination, PHFHEs weigh much less, do not suffer from corrosion, and are likely to be considerably cheaper.

Qin et al. [3] studied PHFHE constructed based on thermal-conductive PP hollow fibers. Heat-conducting PP was prepared by melt-mixing PP with graphite particles and maleated PP. Experimental results confirmed that the addition of graphite fairly improved the crystalline, thermal stability and conductivity of the PP and further improved the heat transfer efficiency of PP PHFHE. The OHTCs up to $1220 \mathrm{~W} / \mathrm{m}^{2} \mathrm{~K}$ were achieved, which is 5 times greater than that of pure PPbased PHFHEs, and the overall conductance per unit volume reached $1.1 * 106$ $\mathrm{W} / \mathrm{m}^{3} \mathrm{~K}$ which is 1.5 times higher than the value of metal shell-and-tube heat exchangers.

Liquid-to-liquid shell-and-tube PHFHE was studied by Yan [5]. Authors improved PHFHE described by Zhao [4] by introducing PP net to improve shellside heat transfer. It has been observed that introducing of the net causes about a $40 \%$ increase of OHTC $\left(650 \mathrm{~W} / \mathrm{m}^{2} \mathrm{~K}\right.$ to $\left.920 \mathrm{~W} / \mathrm{m}^{2} \mathrm{~K}\right)$. Additionally, CFD simulation of both examples was performed and results were compared with experimental data showing sufficient agreement. 
Several aspects concerning large-scale PHFHEs were discussed by Raudenský and Dohnal [6]. The authors described fiber bundle consisting of 30,000 hollow fibers and specified the main difficulty: "each fiber must be active, i.e. each fiber must transfer heat". Two approaches were proposed to fulfill this requirement. The first one is to use fiber overlength i.e. longer fibers than the distance between collecting pottings. The second approach is to use non-straight fibers of a special, "curly" shape. So-called fuzzy fractal analysis was proposed to study fiber curliness and distribution uniformity.

Thermal performance of liquid-to-gas cross-flow heat exchangers were studied by Astrouski and Raudenský [7]. Two types of polypropylene hollow fibers (wall thickness $0.050 \mathrm{~mm}$, outside diameter $0.550 \mathrm{~mm}$ and $0.7 \mathrm{~mm}$ ) were used to create heat exchangers with heat exchange areas $0.2-0.25 \mathrm{~m}^{2}$. An original approach (fiber fabric were woven) was utilized to achieve a uniform distribution of fibers. The heat transfer performance was studied with hot $\left(40-90^{\circ} \mathrm{C}\right)$ ethyleneglycol-water brine flowing inside the fibers and cooling air flowing across the fibers. Experiments showed that hollow fiber cross-flow heat exchangers can achieve high values of overall heat-transfer coefficients $\left(300-600 \mathrm{~W} / \mathrm{m}^{2} \mathrm{~K}\right)$.

Air heat transfer coefficients (HTC) are low and fins are usually used to increase the air-side heat transfer area in metal heat exchangers. However, polymer thermal conductivity is low so such polymer fins are ineffective and the primary heat transfer area of should be large enough. Hollow fibers are tubes of small diameter which can be closely packed within a small volume so packing density (heat transfer area to volume ratio) as much as $3000 \mathrm{~m}^{2} / \mathrm{m}^{3}$ can be achieved. However, this means that many fibers need to be connected, uniformly distributed and supplied with fluid. Poor fiber distribution causes a so-called bypassing of liquid and decreases heat transfer.

Nevertheless, the application of polymers as a material for heat exchangers is infrequent because of the low values of polymer's thermal conductivity. Thin-wall tubes are needed to achieve sufficient thermal performance. The presented study use tubes with outer diameter of $0.6-0.8 \mathrm{~mm}$ and thickness of the wall smaller than $0.06-0.08 \mathrm{~mm}$. Several prototypes of polymeric heat exchangers were prepared and tested in the Heat Transfer and Fluid Flow Laboratory. The results of the experimental investigation are presented in the paper.

\section{Experimental details}

Polymeric hollow fiber based heat exchangers (HEXs) were tested in calorimeter room of Visteon-Autopal (air velocities $1-10 \mathrm{~m} / \mathrm{s}$ ) and in calorimeter room of HeatLab (air velocities $0.2-2 \mathrm{~m} / \mathrm{s}$ ). Two pieces of HEX were tested: N1 was made of $0.6 \mathrm{~mm}$ fibres and N3 was made of $0.8 \mathrm{~mm}$ fibres. Both types of HEX look the same way (see Fig. 1) and described in Tab.1. Tab. 1 represents parameters of ready modules: number of fibers $\mathrm{N}$, fiber length $\mathrm{L}$, outer and inner diameters $\left(\mathrm{D}_{\mathrm{o}}\right.$ and $\left.\mathrm{D}_{\mathrm{i}}\right)$, tube pitches in width and depth $\left(\mathrm{b}_{1}\right.$ and $\left.\mathrm{b}_{2}\right)$, overall heat transfer area based on outer surface $\left(\mathrm{A}_{\mathrm{o}}\right)$ and frontal flow area $\left(\mathrm{A}_{\mathrm{f}}\right)$. Heat exchangers were tested on leaking (pressurised by water up to 3 bar) before thermal performance tests. 


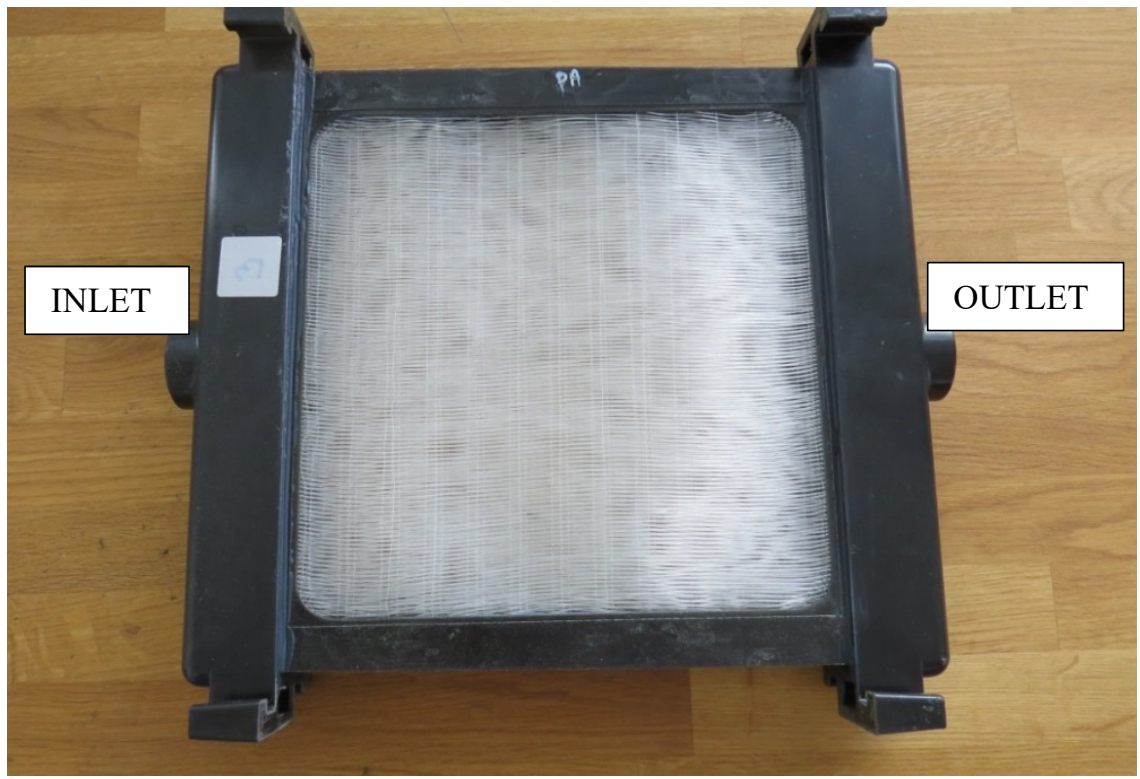

Figure 1: Heat exchangers based on hollow fiber fabric made by pilot-operated link (modules N1 and N3).

Table 1: $\quad$ Parameters of heat exchangers.

\begin{tabular}{|c|c|c|c|c|c|c|c|c|}
\hline $\begin{array}{c}\frac{0}{\Xi} \\
\Sigma\end{array}$ & $N$ & $\begin{array}{c}L \\
(\mathrm{~mm})\end{array}$ & $\begin{array}{c}D_{o} \\
(\mathrm{~mm})\end{array}$ & $\begin{array}{c}D_{i} \\
(\mathrm{~mm})\end{array}$ & $\begin{array}{c}b_{1} \\
(\mathrm{~mm})\end{array}$ & $\begin{array}{c}b_{2} \\
(\mathrm{~mm})\end{array}$ & $\begin{array}{c}A_{o} \\
\left(\mathrm{~m}^{2}\right)\end{array}$ & $\begin{array}{c}A_{f} \\
\left(\mathrm{~m}^{2}\right)\end{array}$ \\
\hline $\mathrm{N} 1$ & 1960 & 250 & 0.6 & 0.48 & 1.8 & 2 & 0.92 & 0.060 \\
\hline $\mathrm{N} 3$ & 1904 & 220 & 0.8 & 0.64 & 1.8 & 2 & 1.05 & 0.053 \\
\hline
\end{tabular}

Calorimeter room of Visteon with heat exchanger installed is presented in Fig. 2. Equipment of calorimeter allows to measure temperatures, flow rates and pressure drops of internal liquid (50\% ethyleneglycol - 50\% water solution) and external air. Temperatures were maintained constant due to cooling and heating sections in both (liquid and air) sides. Temperatures of air were measured by a set of temperature sensors regularly placed in cross-section upstream and downstream of the heat exchanger which gave the approximation of temperature fields.

Calorimeter room of HeatLab allows to measure thermal performance of heating equipment up to $4 \mathrm{~kW}$. The flow rate and inlet temperature of water through the HEX were set up and measured by equipment of calorimeter. Air side tunnels were built to supply HEX by air flow and measure inlet/outlet temperatures. The air flow was created by centrifugal ventilator, regulated by 
shutter, uniformly distributed across channel by perforated net. The air velocity was tentatively measured by anemometer. 9 temperatures (three on inlet and six on outlet) were measured by PT100 temperature sensors (1/3 DIN class of precision) connected to data acquiring system.
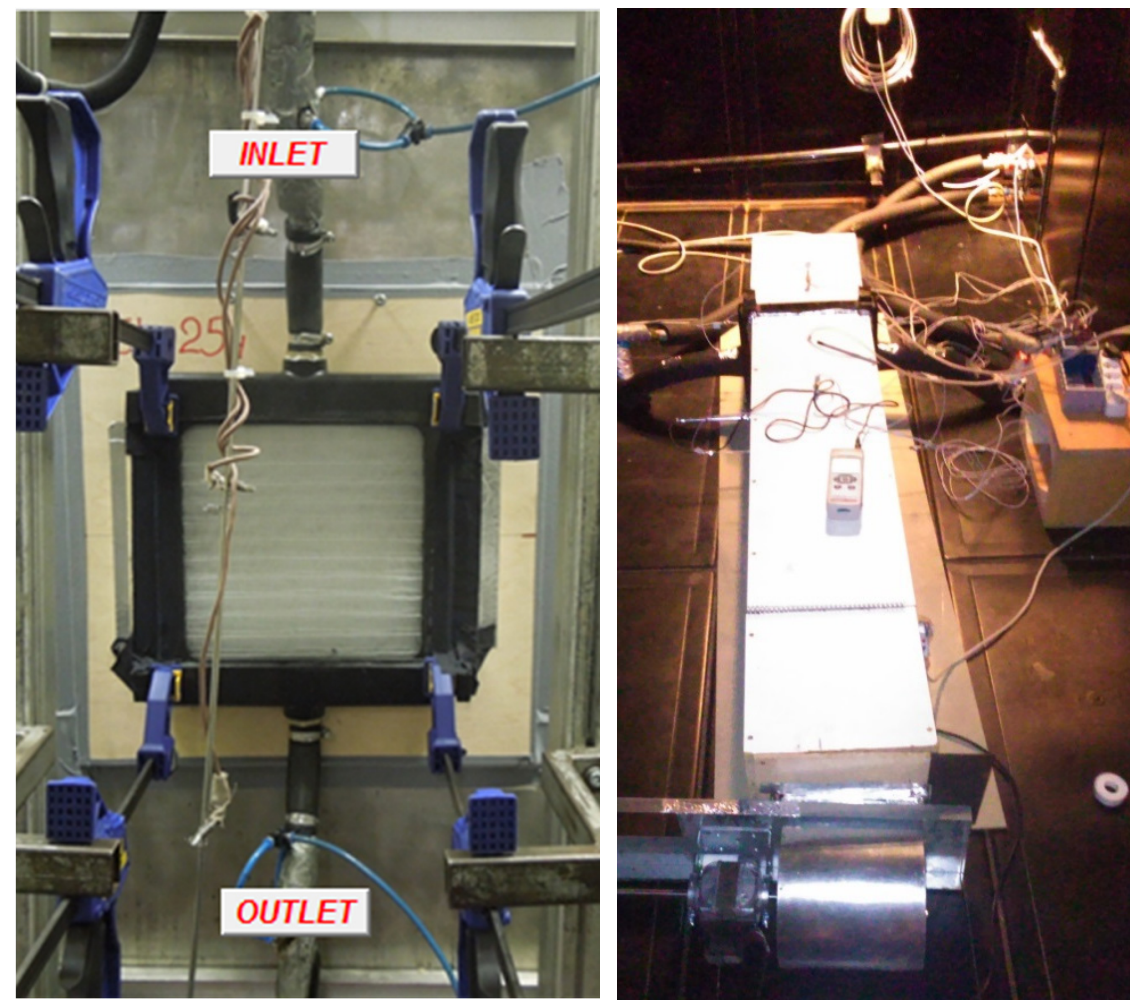

Figure 2: Heat exchanger N1 installed in Visteon calorimeter room (a) and calorimeter room of HeatLab (b) during testing.

\section{Results and discussion}

Results are presented in Tab. 2. These are values of volumetric flow rate and air velocity $\left(\mathrm{v}_{12}, \mathrm{~m}_{34}\right)$, inlet and outlet temperatures $\left(\mathrm{T}_{1}, \mathrm{~T}_{2}, \mathrm{~T}_{3}, \mathrm{~T}_{4}\right)$, pressure drops $\Delta \mathrm{P}$ for both streams. Heat transfer rates is calculated based on data for liquid side. Reduction data results are presented in Tab. 3. These is heat transfer rate Q, logmean temperature difference (LMTD), correction factor for LMTD, overall heat transfer coefficient $\left(\mathrm{U}_{\mathrm{o}}\right)$, efficiency and number of transfer unit (e and NTU).

Reduction data were performed as it was proposed by Zarkadas and Sirkar [1]. Effective mean temperature difference averaged over the total heat exchange area was determined by using logarithmic mean temperature difference (LMTD) and appropriate LMTD correction factor $F$. A correction factor was calculated 
according to Jeter [8]. Air-flow was considered as completely mixed and flow in tubes was considered as completely unmixed. Full data files are available at Heat Transfer and Fluid Flow Laboratory, BUT.

Table 2: $\quad$ Experimental data.

\begin{tabular}{|c|c|c|c|c|c|c|c|c|c|}
\hline & $\begin{array}{c}\text { Measured } \\
\text { by }\end{array}$ & $\begin{array}{l}\mathrm{V}_{12} \\
\mathrm{~m} / \mathrm{s}\end{array}$ & $\begin{array}{l}\mathrm{T}_{1}, \\
{ }^{\circ} \mathrm{C} \\
\end{array}$ & $\begin{array}{l}\mathrm{T}_{2}, \\
{ }^{\circ} \mathrm{C} \\
\end{array}$ & $\begin{array}{c}\Delta \mathrm{P}, \\
\mathrm{Pa}\end{array}$ & $\begin{array}{c}\mathrm{m}_{34}, \\
1 / \mathrm{min}\end{array}$ & $\begin{array}{l}\mathrm{T}_{3}, \\
{ }^{\circ} \mathrm{C}\end{array}$ & $\begin{array}{l}\mathrm{T}_{4}, \\
{ }^{\circ} \mathrm{C} \\
\end{array}$ & $\begin{array}{l}\Delta \mathrm{P}, \\
\mathrm{kPa}\end{array}$ \\
\hline \multirow{9}{*}{ N1 } & \multirow{4}{*}{ HeatLab } & 0.15 & 19.9 & 55.4 & & 2.1 & 60.0 & 57.4 & \\
\hline & & 0.29 & 20.3 & 53.1 & & 2.1 & 60.0 & 55.5 & \\
\hline & & 0.59 & 20.6 & 46.3 & & 2.0 & 60.0 & 52.4 & \\
\hline & & 1.43 & 22.9 & 47.6 & & 2.3 & 59.9 & 44.2 & \\
\hline & \multirow{5}{*}{ Visteon } & 1.0 & 20.5 & 53.6 & 40 & 16.7 & 60.2 & 56.5 & 50.8 \\
\hline & & 2.0 & 20.4 & 50.4 & 77 & 16.7 & 60.3 & 55.5 & 51.2 \\
\hline & & 4.0 & 20.2 & 44.5 & 218 & 16.7 & 60.0 & 53.2 & 52.4 \\
\hline & & 10.0 & 20.2 & 34.7 & 1108 & 16.7 & 59.7 & 49.3 & 55.6 \\
\hline & & 10.0 & 20.1 & 45.6 & 1121 & 16.7 & 90.4 & 72.3 & 36.3 \\
\hline \multirow{3}{*}{ N3 } & \multirow{3}{*}{ HeatLab } & 0.25 & 20.3 & 57.5 & & 2.68 & 60.1 & 56.7 & \\
\hline & & 0.54 & 21.1 & 57.9 & & 2.60 & 60.1 & 52.5 & \\
\hline & & 1.29 & 23.2 & 50.8 & & 2.43 & 60.0 & 45.3 & \\
\hline
\end{tabular}

Table 3: Thermal performance data.

\begin{tabular}{|c|c|c|c|c|c|c|c|}
\hline & $\begin{array}{c}\text { Measured } \\
\text { by }\end{array}$ & $\begin{array}{c}\mathrm{Q} \\
(\mathrm{kW})\end{array}$ & $\mathrm{F}$ & $\begin{array}{l}\text { LMTD } \\
\left({ }^{\circ} \mathrm{C}\right)\end{array}$ & $\mathrm{U}_{\mathrm{o}}\left(\mathrm{W} / \mathrm{m}^{2} \mathrm{~K}\right)$ & e & NTU \\
\hline \multirow{9}{*}{ N1 } & \multirow{4}{*}{ HeatLab } & 0.38 & 0.96 & -15.6 & 27 & 0.89 & 1.90 \\
\hline & & 0.65 & 0.94 & -17.4 & 43 & 0.83 & 1.60 \\
\hline & & 1.05 & 0.95 & -21.5 & 56 & 0.65 & 1.01 \\
\hline & & 2.45 & 0.78 & -16.5 & 202 & 0.67 & 1.51 \\
\hline & \multirow{5}{*}{ Visteon } & 2.4 & 0.95 & -17.4 & 154 & 0.85 & 1.62 \\
\hline & & 4.2 & 0.96 & -19.9 & 237 & 0.74 & 1.25 \\
\hline & & 6.8 & 0.96 & -23.2 & 334 & 0.61 & 0.88 \\
\hline & & 10.3 & 0.97 & -27.0 & 426 & 0.37 & 0.45 \\
\hline & & 18.0 & 0.97 & -48.4 & 416 & 0.36 & 0.44 \\
\hline \multirow{3}{*}{ N3 } & \multirow{3}{*}{ HeatLab } & 0.64 & 0.92 & -12.76 & 52 & 0.94 & 3.16 \\
\hline & & 1.36 & 0.84 & -13.30 & 116 & 0.90 & 3.13 \\
\hline & & 2.45 & 0.75 & -14.75 & 212 & 0.75 & 2.51 \\
\hline
\end{tabular}




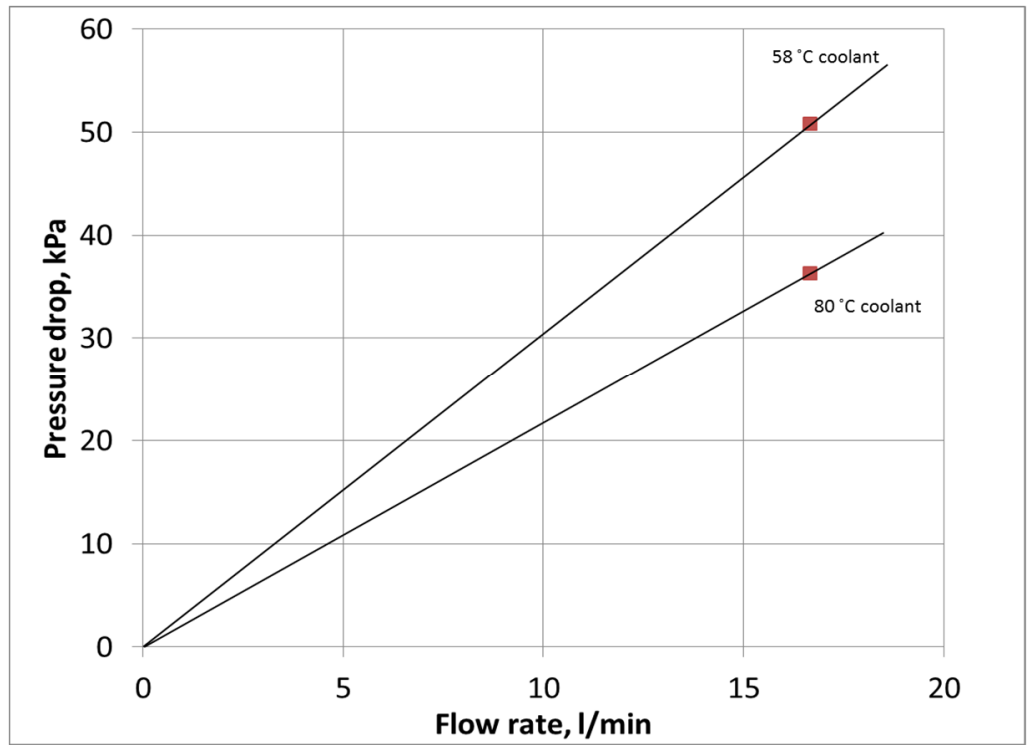

Figure 3: Coolant pressure drop of HEX N1 vs. flow rate. There is linear dependence of pressure drop on the flow rate due to the laminar regime. Moreover, the pressure drop is dependent on the mean liquid temperature because of its dependence on viscosity. The viscosity change due to the temperature significantly influences the pressure drop.

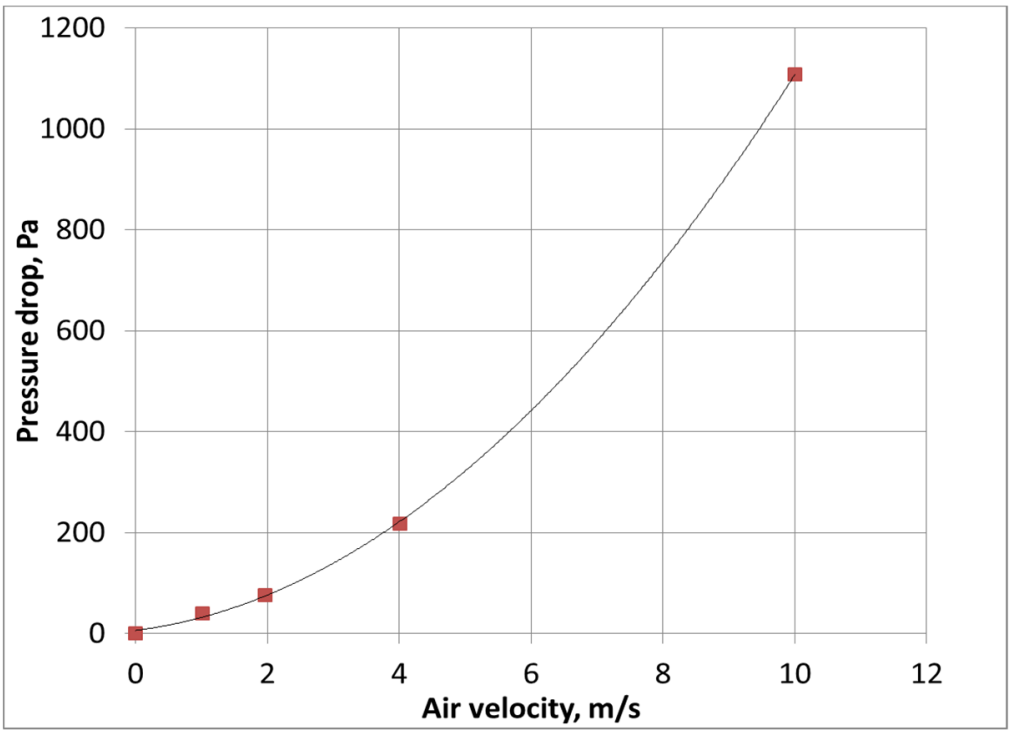

Figure 4: Air pressure drop of HEX N1 vs. air velocity in cross-section (flow rate is $220-2200 \mathrm{~m}^{3} / \mathrm{h}$ ). 


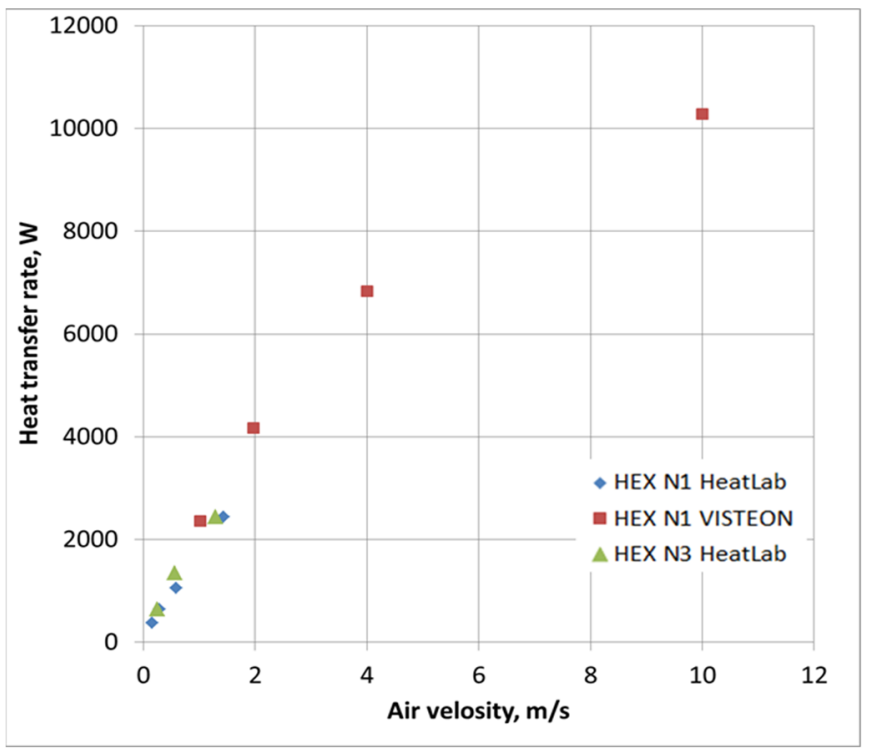

Figure 5: Heat transfer rate vs. air velocity. There is mostly linear dependence of heat transfer rate on air velocity for low velocities (up to $2 \mathrm{~m} / \mathrm{s}$ ) measured in HeatLab. This fact is caused by the large NTU numbers (HEX is too large for such small air quantities).

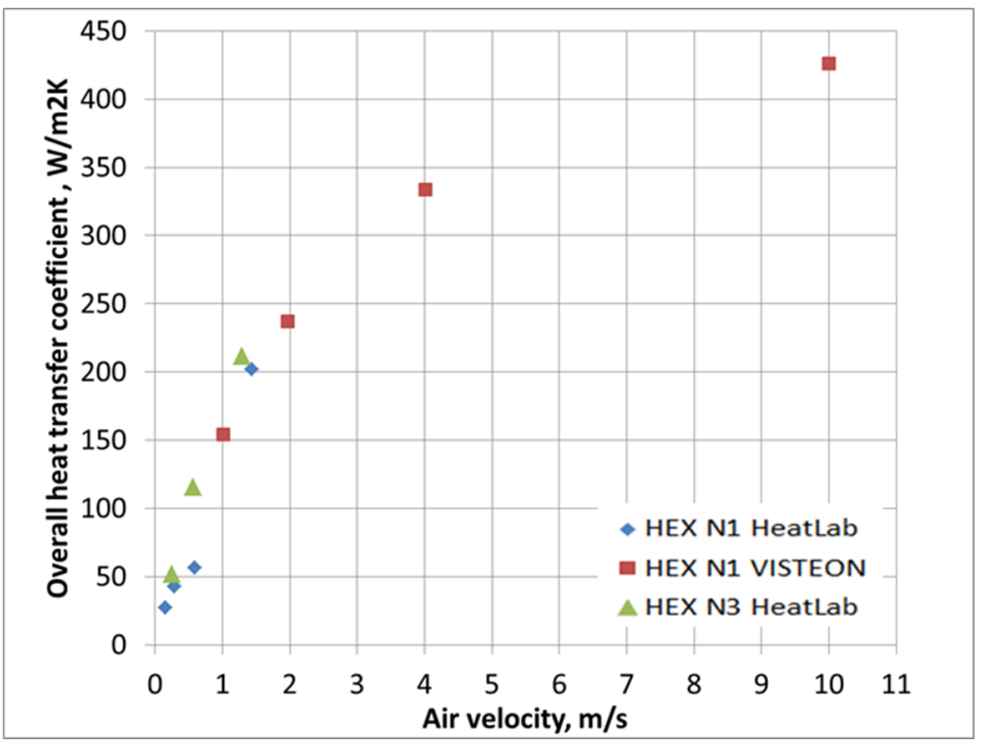

Figure 6: Overall HTC vs. air velocity. There is a trend showing that fibre HEXs achieve high values of overall HTC for relatively low values of air velocity $(0.5-2 \mathrm{~m} / \mathrm{s})$. 


\subsection{Comparison of PHFHEs and conventional finned-tube heat exchangers}

Heat transfer surfaces of modules N1 and N2 were invented to be used as liquidto-gas heat transfer surfaces in different systems. For example, they can be used to replace existing car radiator heat transfer surfaces. Tab. 4 shows (left side) currently widely used heat transfer surface of car radiators. It is made of aluminum flat tubes with aluminum fins brazed to their surface. This design can be considered as very modern and high-efficient; in fact, this technology is very close to being most effective existing solution of liquid-to-gas heat transfer surface. Thus, we assume that if hollow fiber surface will be competitive to such a structure - it will be thermally competitive to the majority of another existing metal liquidto-gas heat transfer surfaces. Tab. 4 presents detailed information about the car radiator and module $\mathrm{N} 1$. We used experimentally obtained results of pressure drops and OHTCs of module N1 to calculate surface-to-air HTC. To estimate parameters of aluminum core of conventional radiators we used thermal performance data of low temperature radiator VPATBH 8005 AA (automotive part of Audi Q7). Fig. 7 presents graphs of pressure drops and air-side HTCs ho of both heat exchanger cores depending on air velocity. We can conclude that the core made out of hollow fibers is very competitive from the point of view of heat transfer. The pressure drops are slightly higher for fiber core but we expect that this drawback can be eliminated by additional optimization of fiber distribution and decomposition.

Table 4: $\quad$ Comparison of parameters of aluminium radiator and module N1.

\begin{tabular}{|c|c|}
\hline $\begin{array}{l}\text { Low temperature radiator LTR } \\
\text { VPATBH } 8005 \text { AA made of } \\
\text { aluminium alloy. Core size is } \\
290 \times 292 \times 25 \mathrm{~mm}, 1 \times 5 \mathrm{~mm} \text { fins on } \\
1.5 \times 25 \mathrm{~mm} \text { flat tubes, } 1.9 \mathrm{~m}^{2} \text { surface. }\end{array}$ & $\begin{array}{l}\text { Module N1, total fiber number is } 1960 \\
(14 \text { layers } 140 \text { each), outer/inner fiber } \\
\text { diameter is } 0.6 / 0.48 \mathrm{~mm} \text {, length } \\
250 \mathrm{~mm} \text {. Core size is } 250 \times 250 \times 40 \mathrm{~mm} \text {, } \\
0.92 \mathrm{~m}^{2} \text { surface. }\end{array}$ \\
\hline \multicolumn{2}{|c|}{ Weight of empty core (without coolant), full core weight and weight ratio: } \\
\hline $933 \mathrm{~g}, 1502 \mathrm{~g}, 100 \%$ & $101 \mathrm{~g}, 396 \mathrm{~g}, 26 \%$ \\
\hline 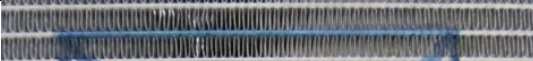 & \\
\hline 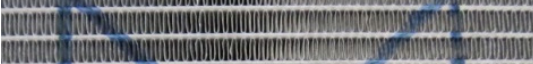 & \\
\hline 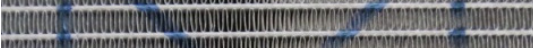 & \\
\hline 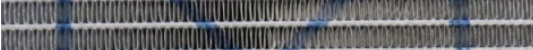 & \\
\hline 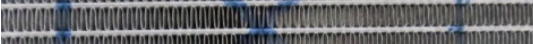 & \\
\hline 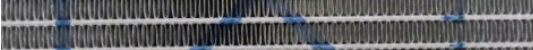 & \\
\hline 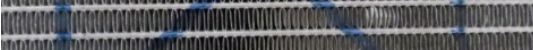 & \\
\hline Intent & \\
\hline 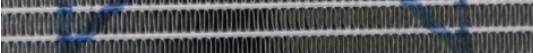 & \\
\hline 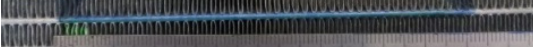 & \\
\hline 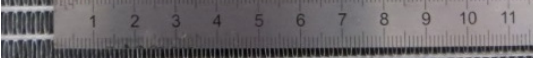 & 1 \\
\hline
\end{tabular}



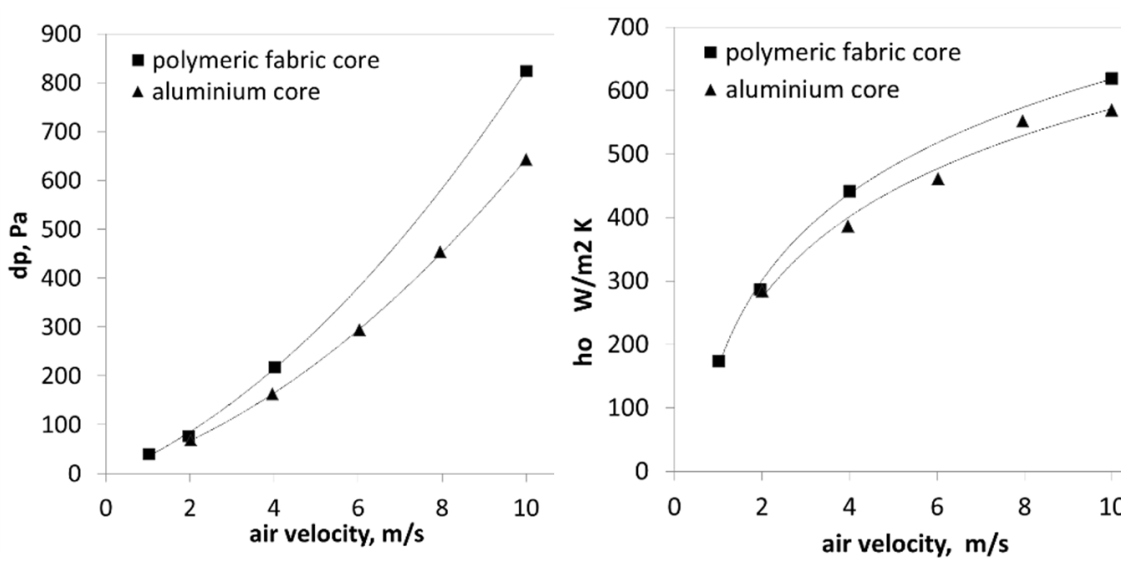

Figure 7: $\quad$ Pressure drops and surface-to-air HTC vs. air velocity for aluminium core of car radiator and core made on fiber fabric (module N1).

\section{Conclusion}

Heat exchangers made of polymeric hollow fibers were made and tested. Unique approach was used to create uniform and dense heat transfer surface: the fibers were woven into fabric. The study of the thermal characteristics showed that these devices can transfer large amounts of heat (tens of kilowatts) in proportion to their volume and weight. Thermal performance tests shown that these devices can achieve high values of overall heat transfer coefficients (up to $400 \mathrm{~W} / \mathrm{m}^{2} \mathrm{~K}$ ).

It can be concluded that the low thermal conductivity of polypropylene not an obstacle to using hollow fibers for gas-to-liquid heat transfer. Moreover, it was shown that, from the point of view of thermal performance, heat transfer surface made of fibers can compete to conventional compact designs used as automotive industry.

\section{Acknowledgement}

The research leading to these results has received funding from the Ministry of Education, Youth and Sports under the National Sustainability Programme I (Project LO1202).

\section{References}

[1] Zarkadas, D., Sirkar K.K. Polymeric Hollow Fiber Heat Exchangers: An Alternative for Lower Temperature Applications. Industrial. 2004, 43(25), 8093-8106. 
[2] Song, L., Li B., Zarkadas D., Christian S., Sirkar K.K. Polymeric HollowFiber Heat Exchangers for Thermal Desalination Processes. Industrial. 2010, 49(23), 11961-11977.

[3] Qin, Y., Li, B., Wang, SH. Experimental Investigation of a Novel Polymeric Heat Exchanger Using Modified Polypropylene Hollow Fibers. Industrial. 2012, 51(2), 882-890.

[4] Zhao, J., Li B., Li X., Qin Y., Li C.H., Wang S.H. Numerical simulation of novel polypropylene hollow fiber heat exchanger and analysis of its characteristics. Applied Thermal Engineering. 2013, 59(1-2), 134-141.

[5] Yan, X., Li B., Liu B., Zhao J., Wang Y., Li H., Analysis of improved novel hollow fiber heat exchanger. Applied Thermal Engineering. 2014, 67(1-2), 114-121.

[6] Raudenský M., Dohnal M., Large scale capillary based plastic heat exchangers, Chemical Engineering Transactions, 29, 2012, 1477-1482

[7] Astrouski, I.; Raudenský, M. Polymeric Hollow Fiber Heat Exchangers: Liquid-to-Gas Application. Proceeding of ASHRAE Annual conference, Seattle, 2014.

[8] Jeter S. M.: Effectiveness and LMTD Correction Factor of the Cross Flow Exchanger: A Simplified and Unified Treatment, ASEE Southeast Section Conference, 2006. 